\title{
Seminal transferrin, a potential human testis biomarker
}

\begin{abstract}
Introduction: Seminal plasma (SP) is a sperm function modulator, for this reason, it is necessary to adequately characterize its molecular composition. Iron (Ir) plays an important role in spermatogenesis. Transferrin $(\mathrm{Tf})$, the cellular membrane receptor for transferrin and ferritin (FN), respectively, are involved in the transport, cellular uptake, and storage of Ir. The metabolic pathways of Ir are still unknown in human testis.

Objectives: The aim of the work was to study biochemical components such as total proteins (TP), Ir, FN and Tf in SP of young individuals, and to establish reference values for our laboratory. These values were then correlated to semen parameters and some sperm functional tests in order to understand the physiology of Ir in the testis.

Materials and methods: Two hundred and fifteen semen and serum samples were studied, and the concentration of Tf, Ir, TP and FN was determined in both fluids. A basic semen analysis and sperm vitality tests were performed. Statistical analysis by the Spearman coefficient ( $\mathrm{r}$ ) for testicular transferrin (TfT) versus each of the quantitative variables of the basic semen analysis was used.

Results and conclusions: It was observed that TfT concentration has a direct relationship with the sperm concentration $(\mathrm{r}=0.3872$, $\mathrm{p}$-value $=0.0070, \mathrm{p}<0.01)$ the total sperm count $(\mathrm{r}=0.515 ; \mathrm{p}$-value $=0.0008, \mathrm{p}<0.01)$ and to a lesser extent with the percentage of progressive motile sperm $(\mathrm{r}=0.3721$; $\mathrm{p}$-value $=0.0139, \mathrm{p}<0.05)$. No correlation with morphology was found. The study of possible biomarkers, such as TfT, would contribute to the knowledge of physiological mechanisms of sperm function, enabling an accurate diagnosis and proper treatment.
\end{abstract}

Keywords: seminal plasma, transferrin, sperm cell, human infertility, biomarker, human testis
Volume 9 Issue 2 - 202|

\author{
Raspo Esteban, ${ }^{1-4}$ Brunori Magalí,, 2 Brufman \\ Adriana $^{1-3}$ \\ 'Immunology reproduction laboratory (LIR), Argentina \\ ${ }^{2}$ Biochemistry and Pharmacy School, National University of \\ Rosario (UNR), Argentina \\ ${ }^{3}$ Research council from National University of Rosario \\ (CIUNR), Argentina \\ ${ }^{4}$ University of Morón (UM), Argentina
}

Correspondence: Raspo Esteban, University of Morón (UM),

24 de Septiembre II 25, Rosario, Santa Fe, Argentina,

Tel+54934I5080076, Email estebanraspo@gmail.com

Received: February 26, 2021 | Published: April 09, 2021
Abbreviations: SP, seminal plasma; Tf, transferrin; RTf, membrane receptor for transferrin; Ir, iron; FN, ferritin; TfT, testicular transferrin; CS, Sertoli cells; RB, reasidual body; CNS, central nervous system; TP, total protein; WHO, world health organization; RID, radial immunodiffusion; LRL, lower Reference Limit; M, mean; SD, standard deviation; CV, coefficient of variation; SFT, seminiferous tubules; SG, spermatogonia

\section{Introduction}

Infertility affects $15 \%$ of couples worldwide. In half of the cases it is related to the male factor. ${ }^{1}$ Semen analysis is the initial step in the study of the male factor. In many cases, the cause of infertility is not identified and is classified as idiopathic, which suggests little knowledge about the mechanisms that regulates spermatogenesis and sperm function. ${ }^{2}$ In these cases, routine semen analysis does not explain fertilization abnormalities, ${ }^{3}$ perhaps due to insufficient knowledge of the basic mechanisms of the reproductive process. ${ }^{4}$

A proper diagnosis of male infertility is of great importance to assess whether or not an abnormality will be passed on to the embryos. Furthermore, there is a necessity to develop better seminal diagnostic biomarkers to assess the success rates of assisted reproductive technologies. A greater understanding in the field of epigenetics is much needed to improve diagnosis and thus develop more personalized treatments for men with idiopathic infertility. ${ }^{5}$

Semen is divided into two main components: the cellular one, which represents $10 \%$ of the total ejaculate volume, and the acellular, generically called seminal plasma (SP). ${ }^{6}$ This fluid contains various components, including lipids, carbohydrates, ions, peptides, and proteins, which are secreted by different regions of the male reproductive tract. It does not only act as a mean of transport, protection and nutrition of sperm, but also as a modulator of sperm function. For this reason, it is necessary to properly characterize the molecular composition of SP.

Seminal plasma proteins perform a wide variety of functions: protection by binding to the sperm surface during ejaculation and playing a key role in the capacitation, acrosome reaction, and fusion of sperm and egg. Because of this specificity it is considered that seminal plasma proteins can serve as important biomarkers for male infertility. ${ }^{7}$ The protein profile of SP is a growing topic, which is greatly enriched by the combination of proteomic analyzes and functional studies which, together, will allow us to discover new cellular pathways that will help provide a better understanding male infertility. The ability to predict fertility using biomarkers is a promising field.

To date, numerous seminal proteins which could be considered important biomarkers for male infertility have been documented, but no noticeable progress has been made in the field. ${ }^{8}$ Iron plays an important role in spermatogenesis. This nutrient is essential but, in excess, it can cause toxicity. Iron transport and its absorption systems are strictly regulated in all organisms dependent on this element. Iron transport, cell uptake, and storage involve Tf, the cell membrane receptor for transferrin (RTf), and ferritin (FN), respectively. Although at the systemic level the metabolic pathways of iron are established, the mechanisms are still unknown in the testis. 
Serum Tf is synthesized mainly by hepatocytes at a concentration of $2.5 \mathrm{mg} / \mathrm{ml}$ and $70 \%$ is found as apotransferrin, not bound to Ir. $^{9}$ It can also be synthesized in cells of the mammary gland, testis, central nervous system (CNS), lymphocytes, and macrophages. $1.5 \%$ of the total proteins in seminal plasma is constituted by an isoform of Tf, called testicular transferrin (TfT), which is secreted by Sertoli cells (CS). ${ }^{10}$ Griswold in $1984,{ }^{11}$ postulated that TfT was involved in the delivery of Ir in developing germ cells. Brotherton and his colleagues ${ }^{12}$ studied variations in seminal Tf results in 1990 with six different commercial kits in 43 apparently healthy individuals and found a very low correlation. With the same objective, Ford ${ }^{13}$ measured serum transferrin levels in 60 chronic kidney patients with the six equipment most commonly used in clinical practice and found a difference in the results of up to $150 \mathrm{ng} / \mathrm{mL}$. In the same study, a biological variation that ranged from 8 to $18 \%$ was found. $\mathrm{FN}$ is an iron-binding molecule, whose main function is to store this element to guarantee its availability in different cellular functions. It also plays an important role in inflammation, neurodegenerative diseases, and cancer (Figure 1).

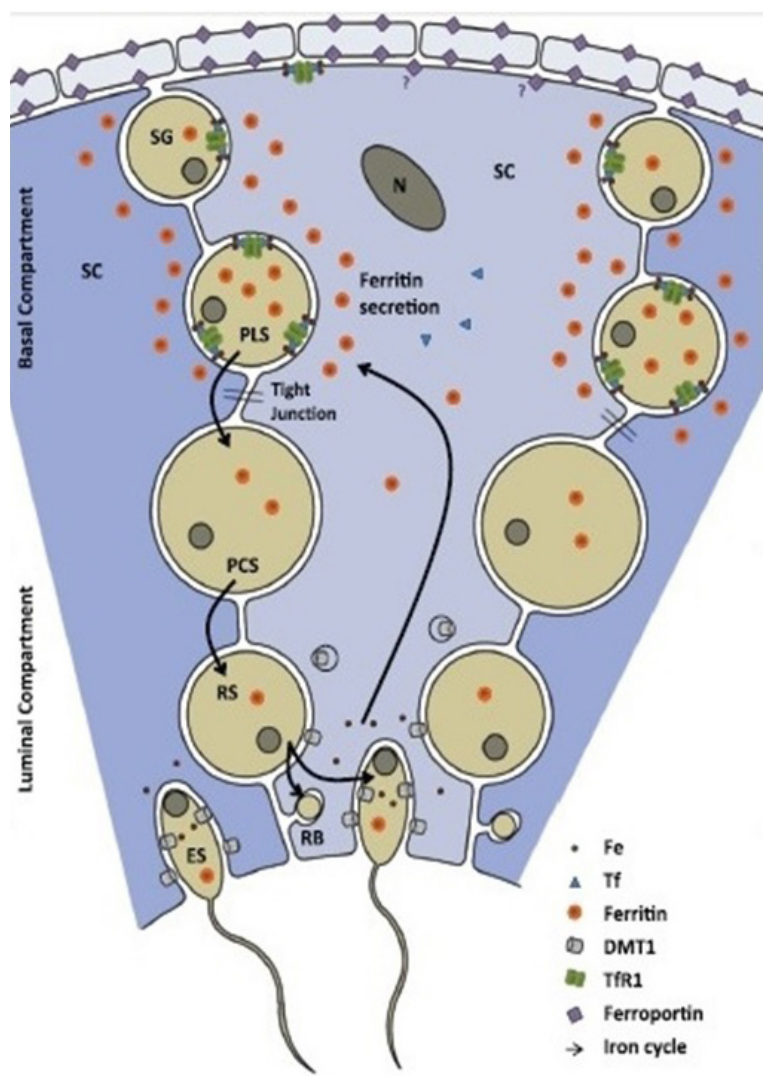

Figure I Shows a model of iron transport in murine testis. ${ }^{14}$

Three CS and their immediate surroundings are shown. Iron transport across the seminiferous tubules (SFT) basal membrane is very limited. Within the SFT some spermatogonia (SG) and mainly primary spermatocytes acquire iron-loaded FN from CS, and upon maturation elongating spermatids return iron to the CS, which traffic it back to a new generation of spermatocytes. Obligatory iron losses through spermatozoa that leave the testis are replenished by the peripheral circulation through the transferrin-TfR1 system. Ferroportin likely plays its main role in iron trafficking across the interstitial space, where selective barriers at the smooth muscle cells of blood vessels and the peritubular myoid cells provide the male germ cells with additional protection from the periphery $\mathrm{RB}$, residual body. ${ }^{14}$
RTf expression is regulated (negatively) at transcriptional level by iron concentration. Thus, with low iron levels, half-life of the translated mRNA is prolonged and the receptor density on the cell membrane increases. As a consequence, Tf uptake by the cell increases and iron requirements are ultimately satisfied. When cellular iron levels are high, the opposite occurs.

\section{Objective}

The aim of the work was to study biochemical components such as $\mathrm{TP}$, Ir, FN and Tf in SP of young individuals, and to establish reference values for our laboratory. These values were then correlated to semen parameters and some sperm functional tests in order to understand the physiology of iron in the testis.

\section{Material and methods}

Two hundred and fifteen semen and serum samples from patients from the Urology Service of "Eva Perón" Training Hospital (Granadero Baigorria), Centenario Hospital (Rosario) and healthy volunteers (age: 36.55 10.44 ) were studied from November 2018 to September 2019. Samples were obtained with the prior informed consent of the patients and controls with the authorization and endorsement of the treating professionals according to Helsinki's declaration. The framework project for this study has the approval of the bioethics committee from the School of Biochemical and Pharmaceutical Sciences, Exp. 6060/368. Res. CD 592/2017. Patients received written instructions for sample collection. Semen samples were collected by masturbation with $48 / 72 \mathrm{~h}$ of abstinence. Seminal samples with low volume $(<1 \mathrm{ml})$ and patients with clinical conditions that could interfere with the levels of Tf and FN in blood plasma such as acute or chronic liver disease, neoplasia, clinical / laboratory signs of infection / acute inflammation or chronic hepatitis virus (A, B or C) infections, leukocytosis, fever, hypoproteinemia and iron metabolism diseases were not included.

\section{Processing of semen samples}

After the liquefaction of semen samples (30-60 min after collection), a complete semen analysis was performed following WHO 2010 guidelines, ${ }^{15}$ which include macroscopic and microscopic examination. Macroscopic examination consists of: volume, appearance, consistency and $\mathrm{pH}$. After examination, two sample aliquots were separated, $300 \mu \mathrm{L}$ for microscopic investigation, and the rest of the semen sample was centrifuged for 30 minutes at 5000rpm to obtain seminal plasma, which was kept refrigerated $\left(-20^{\circ} \mathrm{C}\right)$ for subsequent analysis. In light microscopic (Leica DM500) was evaluated: motility on a thermostated stage with a magnification of $400 x$, agglutination, and vitality with supravital eosin staining. Sperm cell concentration was performed with an improved Neubauer's chamber. Hematoxylin-eosin staining was used to evaluate morphology with immersion lens (1000X).

\section{Preparation of serum samples}

$10 \mathrm{~mL}$ blood collection without anticoagulant was carried out after venipuncture of the upper limb. After exudation (approximately 30 minutes in a water bath at $37^{\circ} \mathrm{C}$ ), blood was centrifuged at 3,500 rpm for 10 minutes. Serum was stored at $-20^{\circ} \mathrm{C}$ until laboratory determinations were made.

\section{Biochemical determinations}

To determinate quantifications, Cobas C501®) analyzer (Roche Diagnostics) was used, measuring the seminal plasma and serum of the patients under study. All reagents and controls were from RocheDiagnostics ${ }^{\circledR}$ : 
Iron quantification: Colorimetric method without deproteinization with Ferrozime (reading at $600 \mathrm{~nm}$ ).Total protein content was assessed using the modified Lowry bicinchoninic acid (BCA) assay, in which amino acid residues from proteins react with copper ions and bicinchoninic acid to produce a color shift which is linear in response to protein concentration. Thus, contaminant sugars, lipids and metabolites will not interfere with protein quantification. ${ }^{16}$ Ferritin evaluation was carried out with Elecsys ${ }^{\circledR}$ Ferritin-Roche electrochemiluminescence immunoassay.

Radial immunodiffusion (RID) technique was used to measure Tf concentration in both fluids. In serum, it was quantified with commercial RID plate DIFFU-PLATE ${ }^{\circledR}$ (Biocientifica SA), to measure Tf in SP, a RID adapted (to low concentrations) plate was developed in our laboratory. For RID plate construction, agarose (Fisher Scientific) $1.5 \mathrm{P} / \mathrm{V}$ in Veronal Sodium-Veronal buffer $(0.02 \mathrm{M}$ with $\mathrm{pH} 8.6$ and $0.005 \mathrm{M}$ sodium chloride) added an specific antibody for Tf (Polyclonal generated in rabbit, Code: OSAX, Dade Behring Inc. Newark, USA) to reach a final concentration of $3.80 \pm 1.30 \mathrm{mg}$ / $\mathrm{dL}($ mean $\pm \mathrm{SD})$.

\section{Sperm vitality test-supravital stain}

Sperm cell vitality estimates the membrane integrity of cells and it's especially important when progressive motile sperm count is less than $40 \%{ }^{15}$ To perform supravital staining, $20 \mu \mathrm{L}$ of homogenized whole semen were placed on a slide and $50 \mu \mathrm{L}$ of eosinY (E4009Sigma Aldrich) $([(0.5 \%(\mathrm{w} / \mathrm{v})$ in $\mathrm{NaCl} 0.9 \%(\mathrm{w} / \mathrm{v})]$. It was observed under a light microscope (Leica DM 500) with a magnification of 400x. Living cells do not incorporate the stain and a white or light pink color is observed while dead cells have a reddish coloration on their heads. Lower Reference Limit (LRL) ${ }^{15}$ for vitality is $58 \%$.

\section{Confirmatory proteomics analysis-western blotting}

\section{Sample preparation}

An alicuot of $100 \mu \mathrm{l}$ of serum an seminal plasma were supplemented with phenylmethylsulfonyl fluoride(PMSF), then, a centrifugation was carried out at $14000 \mathrm{~g}$ at $4^{\circ} \mathrm{C}$ for $15 \mathrm{~min}$. Tf and TfT were selected for confirmatory proteomics analysis by one-dimensional gel electrophoresis (1DGE) followed by western blotting. Briefly, $20 \mu \mathrm{g}$ of seminal plasma and serum proteins were suspended in Milli-Q water, which was diluted 1:1 (v:v) in sample buffer $[0.125$ M Tris-HCl, pH 6.8, 4\% (w:v) SDS, 20\% (v:v) glycerol, 5\% (v:v) beta-mercaptoethanol,0.02\% bromophenol blue] and boiled at 100 ${ }^{\circ} \mathrm{C}$ for $5 \mathrm{~min}$. Proteins were then separated in $10 \%$ polyacrylamide gels under denaturing conditions, and transferred to nitrocellulose membranes through a Wet transfer system (MiniVE; GE Healthcare, Amersham Place, UK). Membranes were subsequently incubated in blocking buffer [ $3 \%$ bovine serum albumin (BSA) in Tris-buffered saline with $0.1 \%$ Tween-20 (TTBS)] for $1 \mathrm{~h}$, washed in TTBS, and incubate with primary antibodies against Tranferrin (sc-21011, Santa Cruz Biotechnology Inc.Santa Cruz, USA) for $2 \mathrm{~h}$ at room temperature. Membranes were then washed with TTBS and incubated with horseradish peroxidase (HRP)-conjugated appropriate secondary antibodies for $1 \mathrm{~h}$ at room temperature. Detection was performed using enhanced chemiluminescence (ECL; GE Healthcare). Signals were detected using an Image- Quant LAS 4000 system (GE Healthcare).

\section{Statistical analysis}

Due to the lack of normality in the distribution between variables the Spearman coefficient was used to verify a possible correlation. For Tf concentrations comparison a categorization into groups was carried out, the non-parametric Mann Whitney test was applied due to non-compliance with the assumption of normality. R Commander $\mathbb{R}$ and Excel (Microsoft Co) programs were used for database. Statistical significance was considered when $\mathrm{p}<0.05$.

\section{Results}

\section{Patient's values}

$\mathrm{S}$ and SP samples were quantified for TP, Tf, Ir and FN according to the methods described above. The results obtained were the following. Table 1 shows obtained values: mean (M), standard deviation (SD) and coefficient of variation (CV) for TP, FN, Ir, Tf in SP. Table 2 shows obtained values: mean (M), standard deviation (SD) and coefficient of variation (CV) for TP, FN, Ir, Tf in serum (Figure 2-3-4)

Table I Metabolites in SP

\begin{tabular}{|c|c|c|c|c|c|c|c|}
\hline Variables in SP & $\begin{array}{l}\text { Minimum } \\
\text { value }\end{array}$ & $\begin{array}{l}\text { Maximun } \\
\text { value }\end{array}$ & Mean (M) & $\begin{array}{l}\text { Standard } \\
\text { deviation (SD) }\end{array}$ & $M \pm S D$ & Median & $\begin{array}{l}\text { Coefficient of } \\
\text { variation (\%) }\end{array}$ \\
\hline Protein $(\mathrm{g} / \mathrm{dL})$ & 0,48 & 5,5 & 2,3 & 0,97 & $2,3 \pm 0,97$ & 2,18 & 42,2 \\
\hline Ferritin (ng/dL) & 20 & 556,3 & 263,1 & 111,12 & $263,1 \pm 111,12$ & 272 & 42,2 \\
\hline Iron ( $\mu \mathrm{g} / \mathrm{dL})$ & 12 & 71 & 30,7 & 13,79 & $30,7 \pm 13,79$ & 28,5 & 44,9 \\
\hline Transferrin (mg/dL) & 1,58 & 16,33 & 4,71 & 3,64 & $4,7 I \pm 3,64$ & 3,35 & 76,9 \\
\hline
\end{tabular}

Table 2 Metabolites in serum

\begin{tabular}{|c|c|c|c|c|c|c|c|}
\hline Variables in serum & $\begin{array}{l}\text { Minimum } \\
\text { value }\end{array}$ & $\begin{array}{l}\text { Maximun } \\
\text { value }\end{array}$ & Mean (M) & $\begin{array}{l}\text { Standard } \\
\text { deviation (SD) }\end{array}$ & $M \pm S D$ & Median & $\begin{array}{l}\text { Coefficient of } \\
\text { variation (\%) }\end{array}$ \\
\hline Protein $(g / d L)$ & 4,31 & 8,47 & 7,17 & 0,74 & $7,17 \pm 0,74$ & 7,24 & 10,3 \\
\hline Ferritin (ng/dL) & 17,2 & 860 & 227,2 & 170,8 & $227,2 \pm 170,8$ & 185,5 & 75,1 \\
\hline Iron $(\mu g / d L)$ & 50 & 186 & 104,1 & 30,7 & $\mid 04, I \pm 30,7$ & 102 & 29,4 \\
\hline Transferrin (mg/dL) & 81,6 & 546,1 & 247,7 & 80,0 & $247,7 \pm 80$ & 210,2 & 32,2 \\
\hline
\end{tabular}




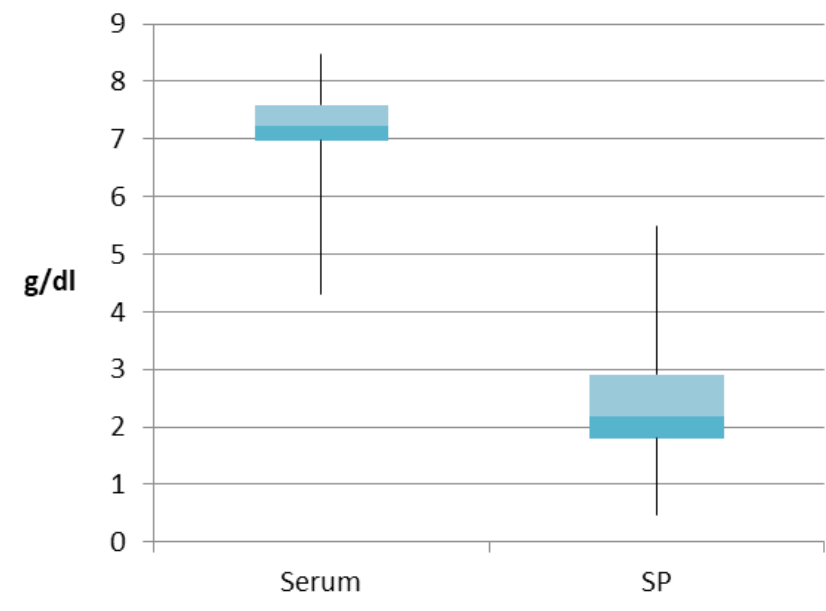

Figure 2 Protein level comparisons on Serum and SP. Pearson correlation coefficient: 0,30999288.

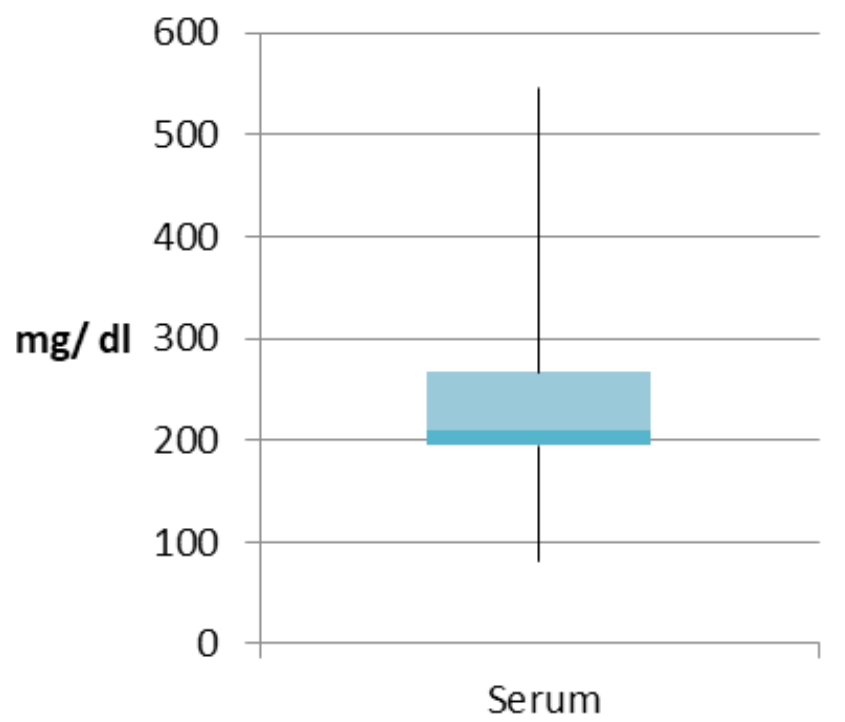

Figure 3 Tf level on serum.

Pearson correlation coefficient: 0,03893283 .

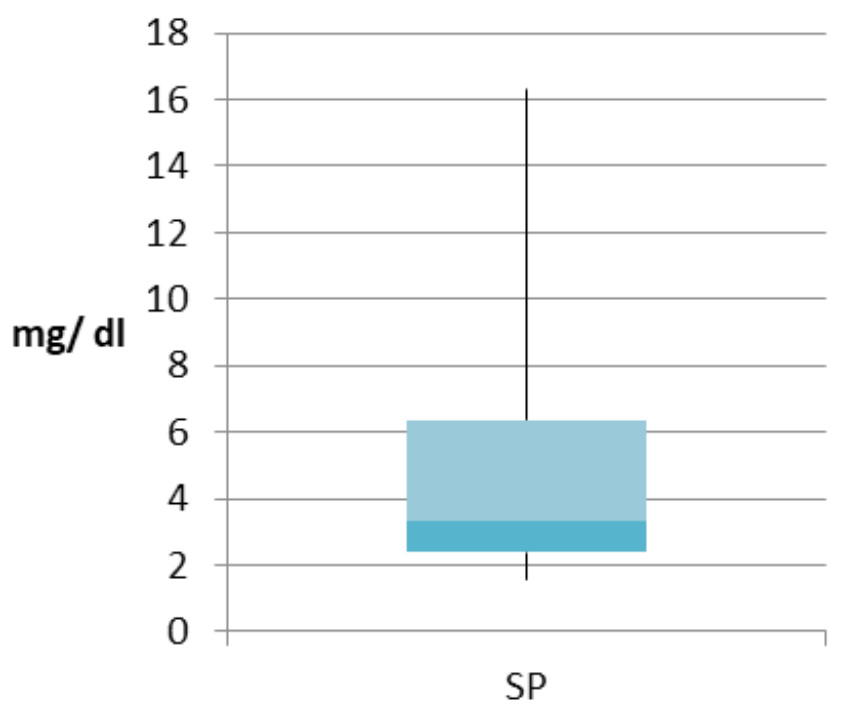

Figure $4 \mathrm{Tf}$ level on SP.

\section{Analysis of variables}

Different samples were selected considering different parameters established for them:

\section{Iron/Transferrin}

Those samples that contained low iron concentration were grouped in order to compare them with transferrin values in SP. It was observed that $82 \%$ of the samples with low iron concentration $(\geq 30 \mathrm{ug} / \mathrm{dL}) \mathrm{did}$ not reach the population mean of Transferrin $(5 \mathrm{mg} / \mathrm{dL})$. Indicating there is a correlation between low iron concentrations and transferrin concentrations below $5 \mathrm{mg} / \mathrm{dL}$.

\section{Iron/Transferrin/Vitality}

To study the relationship between low concentrations of iron and transferrin, compared to sperm cell vitality, we discarded those samples that did not comply with the above described. It was observed that there is no significant correlation between sperm vitality and these variables studied since only $17 \%$ of the samples showed decreased iron and transferrin concentration and low vitality.

\section{Relative concentration/Transferrin}

Relative concentration of sperm cells was studied compared to transferrin concentration. According to the WHO, LRL is 15 million cells per $\mathrm{mL}$. This study was highly significant since none of the selected samples, which did not comply with the LRL, reached the population mean of Transferrin.

\section{Progressive mobility/Transferrin}

Samples with progressive motile spermatozoa below the LRL $(32 \%)$ were selected, correlating them to the concentration of transferrin. When comparing the percentage of progressive mobility with the concentration of transferrin in SP, we could observe that $85 \%$ did not reach the population mean.

To achieve a better visualization of diffusion halos, plates were stained with Amido Black (BioSystems) for 5 min and washed with decolorizing solution [acetic acid $25 \%(\mathrm{v} / \mathrm{v}) ; 40 \%$ methanol (v/v)]. Reading was made with a millimeter magnifying glass $(0.1 \mathrm{~mm}$ precision) with a 10x magnification. Tf concentration is calculated using the following calibration curve: $\mathrm{D} 2=0.6702 \times[\mathrm{Tf}]+1.41651$, $\mathrm{R} 2=0.9839$. Where $[\mathrm{Tf}]$ is the concentration of $\mathrm{Tf}$ in $\mathrm{mg} / \mathrm{dL}$ and $\mathrm{D} 2$ is the squared diameter of the diffusion halo (Figure 5).

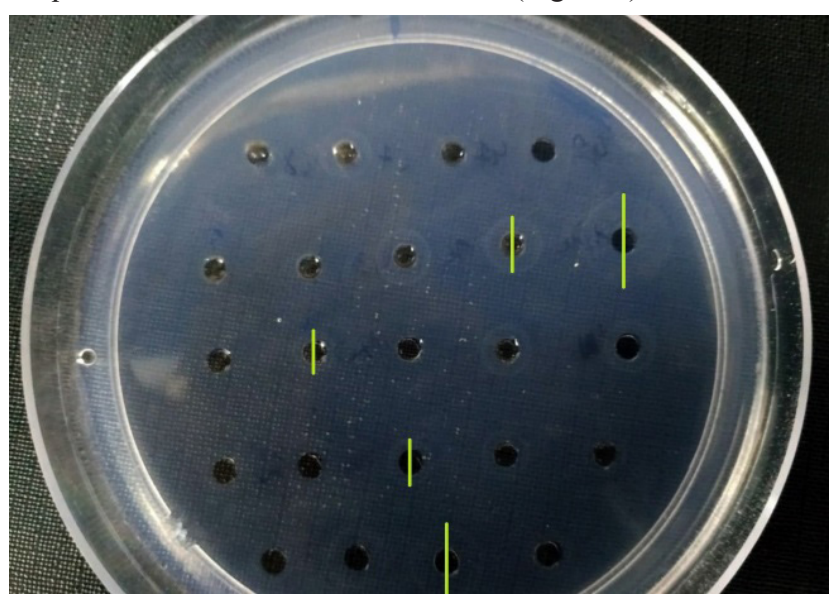

Figure 5 Transferrin concentration in SP. Samples measurement in laboratory designed plate. Example of halo diameters created by different samples according to its $\mathrm{Tf}$ concentration gel not stained. 
Example of Immunodetection of Tf using anti-Tf antibody. Serum sample was dilute $1 / 100$ and SP sample was dilute $1 / 2$, both samples from the same patient. Lane 1: human serum (dilution 1/100), Lane 2: Negative control. Lane 3: Seminal plasma (dilution 1/2). Bands below correspond to loading control staining with Ponceau S. Under the assumption that murine TfT has been evidenced as responsible for iron transport in SFT we set out to corroborate it by immunodetection with the Western Blot technique (Figure 6).

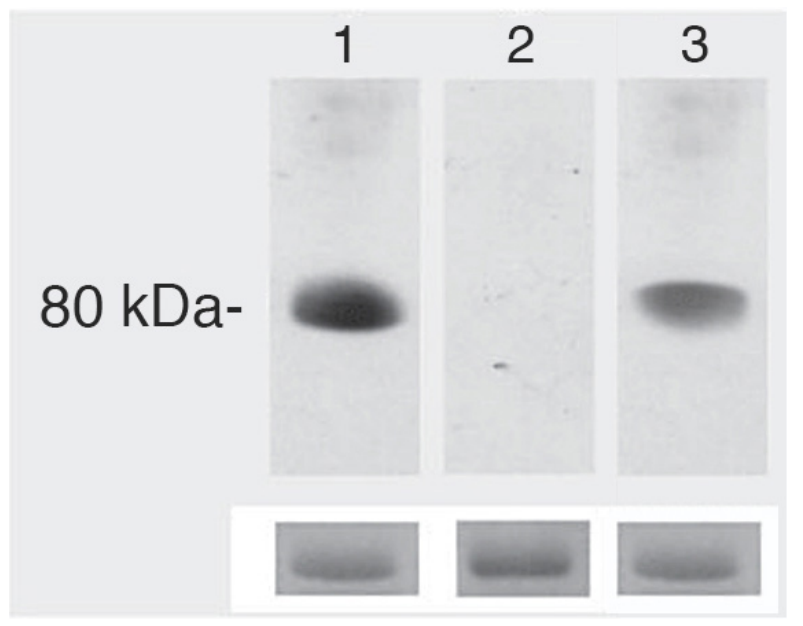

Figure 6 Characterization of testicular transferrin by western blot.

\section{Discussion}

Male infertility is a widespread medical condition with great social and emotional costs, and male factor is related in no less than $50 \%$ of these cases. The etiology of male infertility is multifactorial and often unknown. Basic semen analysis is the cornerstone in evaluating male factor infertility. However, this routine test does not provide information regarding sperm cell development and function. For this reason, it is necessary to identify biomarkers in seminal plasma to acquire more information about the metabolic and molecular processes of the male gamete.

In previous studies, very different values of metabolites Ir, Tf, FN and TP in SP were observed, for this reason it is necessary to have our own calculated reference values from our population and methodology to deepen in the knowledge of the homeostasis of the iron in testis. In our work, the studied biochemical markers were significantly different in seminal plasma and serum, and no relationship was found between them. These differences may be associated with the selective secretion of the testis, epididymis and male accessory glands and, also, the specific environment required for metabolism and maintenance of sperm function. In order to evaluate $\mathrm{Tf}$ as a possible biomarker, we related its concentration in PS in a heterogeneous group (composed of individuals with some andrological pathology and likely healthy controls), with quantitative variables of the basic semen analysis of greater clinical relevance.

According to Fuse, ${ }^{17} \mathrm{SP}$ transferrin concentrations were decreased in hypergonadotropic oligozoospermic subjects and in men with azoospermia due to germ cell injury. The positive correlation, demonstrated in previous studies, between TfT concentration and sperm concentration and the decreased levels of this protein in patients with oligozoospermia confirms this. ${ }^{18}$ Skinner and Griswold ${ }^{19}$ assumed that Sertoli cells (SC) serve as intermediaries in the transport of iron from serum transferrin to developing germ cells. It was also shown that the growth promoting effect of this protein can be explained by its role in the supply of iron to testicular cells. Transferrin was further reported to bind to spermatocytes with high affinity. These findings indicate, once again, that transferrin plays an important role in the development and differentiation of spermatogenic cells.

As stated by Barthelemy, ${ }^{20}$ transferrin concentrations in vasectomized patients were significantly lower (approximately 5 times) than in normozoospermic men or proven fertile donors. This difference suggests that the main source of seminal fluid transferrin is testicular, as previously suggested. ${ }^{21}$ The remainder of the transferrin can originate from secretion of the prostate and/or seminal vesicles and/or serum transudation. However, the lack of a correlation between blood and seminal transferrin suggests low participation of serum component. ${ }^{21}$ In our results, we also found no relationship between these variables.

All the analyzed works date back more than ten years. Since then none categorical conclusion has been reached regarding the function of Transferrin as a modulator/ marker molecule of testicular function. In addition, studies related to iron transport have been performed in murine models. The murine model is very useful for studying many molecular and biochemical processes associated with the formation of sperm cells. These studies do not always correlate with those of humans. Due to the apparent evolutionary divergences in fertilization events, it is important to study the intervening structures in each particular species. ${ }^{22}$

In order to validate in humans the proposed specific synthesis of a $\mathrm{Tf}$ isoform by Sertoli cells in murine model we performed a Western Blot. Only measurements of seminal androgen-binding protein (ABP), another protein secreted by the testis, can be considered a functional marker specific to this structure. However, the ABP assay is time consuming and the concentration of this protein in semen is very low. For this reason, it would be very interesting if transferrin measurement could be considered as a possible indicator method of testis function.

Tf concentration was significantly lower in samples with low vitality and no correlation was found with morphology. Concentration of sperm cells was studied and compared with the samples' transferrin concentration levels. (According to the WHO, the LRL is 15 million cells per $\mathrm{mL}$ ). This study was highly significant since none of the selected samples, under LRL, reached Transferrin population mean. In addition, samples which did not reach LRL for progressive motile spermatozoa $(32 \%)$ were selected, correlating them to transferrin concentration; we could observe that $85 \%$ did not reach the population mean.

We postulate that the decrease in the concentration of Tf in PS could be associated with abnormal spermatogenesis leading to a decrease in the number and mobility of spermatozoa. Other researchers ${ }^{23,24}$ have studied the antioxidant function of metal-transporter proteins which is believed to play an important role on the integrity and function of sperm cells. We are now studying the oxidative stress of sperm cells, evaluating peroxidation on the lipid membrane and/ or determining the concentration of superoxide dismutase in PS in order to obtain conclusive data.

\section{Limitations}

In this study, only proteins involved in the metabolism of iron as biomarkers of testis function and its possible application for the diagnosis of male infertility are analyzed. Specific studies will be required to validate the biomarker status of other organs which also participate in the production of SP. Other types of markers deserve special attention given their potential predictive value for specific 
pathological situations, for example, in prostate cancers. Using an integrative genomics approach, we will identify candidate biomarkers for each of the organs involved in the reproductive process.

\section{Conclusion}

The studied biochemical markers were significantly different in seminal plasma and serum, and no relationship was found between them. Anomalies of many sperm cell functions might be due to the action of a number of factors. Knowledge of the pathophysiological mechanisms of these factors is of great importance for the treatment choice. A more in-depth study of TfT will allow, perhaps, considering it as a possible biomarker of testicular function

\section{Acknowledgments}

To the patients who participated in the project. To urologist doctor Esteban Streiger, for his collaboration in data collection. To Ms. Alejandra Olmos for her assistance in the statistical processing.

\section{Conflicts of interest}

Authors declare that there is no conflict of interest.

\section{References}

1. Sharma R, Agarwal A, Mohanty G, et al. Functional proteomic analysis of seminal plasma proteins in men with various semen parameters. Reprod Biol Endocrinol. 2013;11:38.

2. Brufman AS. Caracterización de los antígenos ABH en la membrana espermática humana. Publicia; 2016. 27 p.

3. Kumar N, Singh AK. Reactive oxygen species in seminal plasma as a cause of male infertility. J Gynecol Obstet Hum Reprod. 2018;47(10):565-572.

4. Suryandari D, Midoen Y, Yunaini L, et al. Decreased Expression of CDC25A in Azoospermia as the Etiology of Spermatogenesis Failure. $J$ Reprod Infertil. 2018;19(2):100-108.

5. Bracke A, Peeters K, Punjabi U, et al. A search for molecular mechanisms underlying male idiopathic infertility. Reproductive Biomedicine Online. 2018;36(3):327-339.

6. Rodríguez-Martínez H, Kvist U, Ernerudh J, et al. Seminal plasma proteins: what role do they play? Am J Reprod Immunol. 2011;66 Supp $1: 11-22$.

7. Samanta L, Parida R, Dias TR, et al. The enigmatic seminal plasma: a proteomics insight from ejaculation to fertilization. Reprod Biol Endocrinol. 2018;16(1):41.

8. Macanovic B, Vucetic M, Jankovic A et al. Correlation between sperm parameters and protein expression of antioxidative defense enzymes in seminal plasma: a pilot study. Dis Markers. 2015;2015:436236.
9. Xiu-Lian D, Kui W, Ya K, et al. Apotransferrin is internalized and distributed in the same way as holotransferrin in K562 cells. $J$ Cell Physiol. 2004 ;201(1):45-54.

10. Sylvester SR, Griswold MD. The testicular iron shuttle: a "nurse" function of the Sertoli cells. J Androl. 1994;15(5):381-385.

11. Sylvester SR, Griswold MD. Localization of transferrin and transferrin receptors in rat testes. Biol Reprod. 1984;31(1):195-203.

12. Brotherton J. Ferritin: another pregnancy-specific protein in human seminal plasma and amniotic fluid, as estimated by six methods. Andrologia. 1990;22(6):597-607.

13. Ford BA, Coyne DW, Eby CS, et al. Variability of ferritin measurements in chronic kidney disease; implications for iron management. Kidney Int. 2009;75(1):104-110.

14. Leichtmann-Bardoogo Y, Cohen LA, Weiss A, et al. Compartmentalization and regulation of iron metabolism proteins protect male germ cells from iron overload. Am J Physiol Endocrinol Metab. 2012;302(12):E1519-1530.

15. World Health Organization. WHO laboratory manual for the examination and processing of human semen; 2010.

16. Smith PK, Krohn RI, Hermanson GT, et al Measurement of protein using bicinchoninic acid. Anal Biochem. 1985;150(1):76-85.

17. Fuse H, Okumura M, Kazama T, et al. Correlation of seminal plasma transferrin concentration and hypoosmotic swelling of the sperm. Arch Androl. 1994;32(2):95-100.

18. Yoshida KI, Nakame Y, Uchijima Y. Seminal plasma transferrin concentration in normozoospermic fertile men and oligozoospermic men associated with varicocele. Int J Fertil. 1988;33(6):432-436.

19. Skinner MK, Cosand WL, Griswold MD. Purification and characterization of testicular transferrin secreted by rat Sertoli cells. Biochem J. 1984;218(2):313-320.

20. Barthelemy C, Khalfoun B, Guillaumin JM, et al. Seminal fluid transferrin as an index of gonadal function in men. $J$ Reprod Fertil. 1988;82(1):113-118.

21. Holmes SD, Lipshultz LI, Smith RG. Transferrin and gonadal dysfunction in man. Fert Steril. 1983;38(5):600-604.

22. Diekman AB. Glycoconjugated in sperm function and gamete interaction: How much sugar does it take to sweet-talk the egg?. Cell Mol Life Sci. 2003;60(2):298-308.

23. Levy MA, Tsai YH, Reaume A, et al. Cellular response of antioxidant metalloproteins in $\mathrm{Cu} / \mathrm{Zn}$ SOD transgenic mice exposed to hyperoxia. $\mathrm{Am}$ J Physiol Lung Cell Mol Physiol. 2001;281(1):172-182.

24. Agarwal A, Durairajanayagam D, Halabi J, et al. Proteomics, oxidative stress and male infertility. Reprod Biomed Online. 2014;29(1):32-58. 